\title{
Modelling the wasted value of data in maintenance investments
}

\begin{tabular}{|r|l|}
\hline Journal: & Journal of Quality in Maintenance Engineering \\
\hline Manuscript ID & Draft \\
\hline Manuscript Type: & Research Paper \\
\hline Keywords: & Maintenance cost management, Value creation, Maintenance process \\
\hline \multicolumn{2}{|c|}{} \\
\hline
\end{tabular}




\title{
Modelling the wasted value of data in maintenance investments
}

\begin{abstract}
Purpose - Big data and related technologies are expected to drastically change the way industrial maintenance in managed. However, at the moment many companies are collecting large amounts of data without knowing how to systematically exploit it. It is therefore important to find new ways of evaluating and quantifying the value of data. This paper addresses the value of data -based profitability of maintenance investments.
\end{abstract}

Design/methodology/approach - An analytical Wasted Value of Data -model is presented to quantify how the value of data can be increased through eliminating waste. The use of the model is demonstrated with a case example of a maintenance investment appraisal of an automotive parts manufacturer.

Findings - The presented model contributes to the gap between the academic research and the solutions implemented in practice in the area of value optimization. The big data hype has led organizations into gathering data without systematic exploitation plans, but it is crucial to evaluate if the benefits of the investment will exceed the additional costs.

Originality/value - The model is designed and developed on the principle of eliminating waste to increase value, which has not been previously extensively discussed in the context of data management.

Article classification - Research paper

Keywords: Maintenance cost management; Value creation; Maintenance process

\section{Introduction}

Industrial maintenance is expected to be revolutionized by the recent manufacturing-related technological developments. The emergence of concepts such as Industry 4.0, cyber-physical systems, and big data has boosted the need to exploit data in maintenance decision making (Kamble et al., 2018). This includes using various supportive technologies for example in non-destructive degradation assessment, prognostics, remote maintenance, and task visualization (Roy et al., 2016). As a result of this technological development, the information technology landscapes connected to the asset lifecycles are complex, heterogeneous, and often include various systems and stakeholders (E1 Kadiri et al., 2016). The complexity together with the big data hype has resulted in a situation where many companies are examining the need to collect big data without a specific purpose or a systematic data exploitation plan, which often leads to the maintenance decision makers feeling overwhelmed and unable to exploit the data (Günther et al., 2017). 
Chen et al. (2015) describe big data as 'a hammer looking for nails' because it can provide solutions to an undefined range of decision-making situations. It can be argued that achieving widespread value from big data often requires the use of extensive resources. Konecranes, a global provider of industrial lifting equipment and solutions, is an example of an organization that are excelling in embedding big data into their maintenance business. They have connected over 19,000 assets world-wide with their remote monitoring center, providing them sensor-based real time usage data to support their customers with, for example, remote maintenance, maintenance planning, prognostics, automatic warehouse management, and analytics services. In the future they are striving for an increase in digital operations in their equipment and service business with increased use of artificial intelligence, machine-learning, economies of scale through an ever larger fleet of intelligent assets, and eventually autonomous assets (Konecranes, 2018). However, many organizations do not have the resources and competence to extensively experiment with big data and the related technologies. This is emphasized by the low technology maturity of the manufacturing and maintenance industries reported by Diez-Olivan et al. (2019) and Kans (2013). Günther et al. (2017) state that a majority of the existing literature on big data has focused on its benefits without sufficient critical discussion, and that it is easy for decision makers in industry to forget that the value from big data needs to surpass the resources required to collect, analyze, and exploit the data. To support maintenance decision making, it is important to evaluate and quantify the value of data.

The objective of this paper is to develop a method to assess the value of data -based profitability of maintenance investments. This objective is pursued through analytical modelling. A Wasted Value of Data -model (WVD-model) is developed on the concept of increasing value through eliminating waste, which is an integral part of lean maintenance data management. The use of the model is presented through a case example of a maintenance investment idea developed within an industrial manufacturing company. Kleinberg et al. (1998) describe the value optimization problems often addressed in microeconomics and mathematical programming to be so complex and unknown that there is a wide gap between the academic research and the solutions implemented in practice: the managerial contribution of the research-based models is often limited to providing heuristic guidelines, whereas company decision makers rely on their subjective and limited knowledge of the problem. The research approach adopted in this paper will decrease this gap in the context of maintenance decision making support in terms of contributing to the existing theories of lean management, maintenance processes, and data management, while ensuring the model is easy to use and adaptable to provide possibilities for practical implementation in industry.

\section{Value of data-based maintenance investments}

\subsection{Data-based maintenance investments}


In this paper maintenance investments mean organizations investing their resources in developing certain aspect(s) of their maintenance functions. It is therefore different from investing in new assets or machines, which is also closely related to maintenance. The existing literature has not explicitly defined maintenance investments, nor presented taxonomies. Alsyouf (2009) stated that maintenance investments can be directed at people, training, or technology. This is somewhat congruent with the ISO 55001 standard (2014), which lists that asset management systems are built upon resources, competence, awareness, communication, information requirements, and documented information. According to Tam and Price (2008), organizations should maximize the return on their maintenance investments by the optimization of three specific decision dimensions: output dimension (achieving objectives related to production, service delivery, and compliance), risk dimension (achieving objectives related to unexpected faults and failures), and resources dimension (achieving objectives related to cost-efficient supply of supporting resources). It can be stated that maintenance investments aim at objectives related to one or more of these dimensions. All three dimensions should be taken into account in investment decision making, although the importance of individual dimensions is system dependent.

Data is an integral part of an increasing share of maintenance investments, as the amount of data available to support maintenance decision making is ever increasing (Baglee et al., 2015; Candell et al., 2009). Data is used to build maintenance decision-support models and predictions, and to construct history databases to ensure the reliability of the adopted decision logics (Takata et al., 1999). The optimal amount of data to be collected to support maintenance decision making varies depending on the size, business, asset and process complexity, and competence of the organization (BS ISO 55001, 2014). To optimize maintenance investment decisions, it would be important to be able to assess the value of data in various maintenance-related decision making contexts. The existing academic discussion on defining and quantifying the value of data is fragmented. Examples exist in the contexts of financial investment decisions (Kadan \& Manela, 2018), biology and ecology (e.g. disease control, threatened species management) as well as economics through the value of information -theory (Alfonso et al., 2016; Bennett et al., 2018). Bucherer and Uckelmann (2011) state that the value of information services consists of having the right information, in the right amount, quality, format, time, place, and for an appropriate price. This view approaches information as a factor of production, which has been discussed in various development stages of modern information technology (see e.g. Dewan \& Min, 1997; Imran et al., 2018). However there is limited research to support presenting Bucherer and Uckelmann's statement in a quantifiable format to provide managerial guidance for the companies' decision makers.

\subsection{The value of lean maintenance data}


The increased amount of data provides new possibilities for data-based decision making in maintenance, but it also brings forward challenges. The decision makers can feel overwhelmed by the vast data, and the process of gathering, analyzing and exploiting data is managed sub-optimally (Kinnunen et al., 2016). To make the waste caused by data overload transparent, a lean data approach can be suggested. Lean, within the context of manufacturing, is a management approach built on maximizing value through eliminating waste (Gupta et al., 2016), which has been widely discussed in the context of managing the material flows of manufacturing systems. Lean management has also been adapted to service processes (Andersson et al., 2015; Jylhä \& Junnila, 2013), and software projects (Staats et al., 2011), but the discussion on lean data management are somewhat limited at best (see e.g. Bevilacqua et al., 2015; Hicks, 2007; Keltanen, 2013; Obeysekare et al., 2016).

Summarizing the existing body of knowledge on waste in lean production (Andersson et al., 2015), lean maintenance (Huang et al., 2012; Mostafa et al., 2015), and lean information management (Hicks, 2007; Verhagen et al., 2015), previous research has presented eight types of waste in maintenance data management processes:

1) Unnecessary data in decision making,

2) Unnecessary data in other parts of the data management process,

3) Unnecessary transfer of data,

4) Unnecessary processing of data,

5) Underutilized data management resources,

6) Incorrect data,

7) Incorrect analysis, and

8) Waiting for data and decision making (Marttonen-Arola \& Baglee, 2019).

Erkoyuncu et al., (2017) note that the majority of maintenance models are focused on specific cases and tend to optimize direct maintenance efforts with expected savings, without taking the resources used in collecting data and developing new methods into account. In this paper we argue that to evaluate databased maintenance investments and optimize the output, risk, and resource dimensions, it is necessary to quantify the costs and benefits of the data management process. The next section presents the WVDmodel to analyze the investments based on the information wastes listed above.

\section{Wasted Value of Data -model for evaluating maintenance investments}

\subsection{Calculating the annual net value}


To assess the profitability of data-based maintenance investments, we begin by evaluating the annual value generated by the investment, based on the various waste types listed above:

$$
V=\sum_{y=1}^{5} V_{y}+(1-\alpha) * V_{6}
$$

where $V$ is the additional annual value generated by the investment, excluding the actual investment costs,

$V_{l}$ is the value of the investment generated by decrease of unnecessary data in decision making,

$V_{2}$ is the value of the investment generated by decrease of unnecessary data in other parts of the data management process,

$V_{3}$ is the value of the investment generated by decrease of unnecessary transfer of data,

$V_{4}$ is the value of the investment generated by decrease of unnecessary processing of data,

$V_{5}$ is the value of the investment generated by decrease of underutilised data management resources,

$\alpha$ is an uncertainty coefficient generated by incorrect data and/or analyses, and

$V_{6}$ is the value of the investment generated by decrease of waiting for data.

It should be noted that the maintenance investment could generate an increase in a number of the waste types. An example of this would be adopting an advanced data system which records data unnecessary to the maintenance decision makers, causing $V_{l}$ and $V_{2}$ to become negative and decrease the annual net value. In the next paragraphs the components of value in equation (1) are discussed in further detail. First of all, the value generated by decrease of unnecessary data in decision making can be defined as

$$
V_{1}=\left(t_{1 a}-t_{1 b}\right) * c_{1}
$$

where $t_{l a}$ is the time used in the decision making process before the investment, $t_{l b}$ is the time used in the decision making process after the investment, and

$c_{l}$ is the cost of the time of the decision maker.

Similarly, the value generated by decrease of unnecessary data in other parts of the process, unnecessary data transfer, and unnecessary data processing can be defined as in equations (3) to (5).

$$
V_{2}=\left(t_{2 a}-t_{2 b}\right) * c_{2}
$$


where $t_{2 a}$ is the time used in the data management process before the investment,

$t_{2 b}$ is the time used in the data management process after the investment, and

$c_{2}$ is the cost of the time of the personnel managing the data.

$$
V_{3}=\left(t_{3 a}-t_{3 b}\right) * c_{3}
$$

where $t_{3 a}$ is the time used in transferring the data before the investment,

$t_{3 b}$ is the time used in transferring the data after the investment, and

$c_{3}$ is the cost of the time of the person transferring the data.

$$
V_{4}=\left(t_{4 a}-t_{4 b}\right) * c_{4}
$$

where $t_{4 a}$ is the time used in processing the data before the investment,

$t_{4 b}$ is the time used in processing the data after the investment, and

$c_{4}$ is the cost of the time of the person processing the data.

In addition to the data, the resources required for data-based maintenance include various maintenance systems and personnel. The capacity and potential underutilisation of resources is easy to overlook in investment decision making but it can have a significant impact on the profitability of the investment. According to Wienker et al. (2016), only 6\%-15\% of the users of Computerized Maintenance Management Systems (CMMS) exploit the systems at their full capacity. Many organizations purchase features and applications that they rarely or never use. Regarding the personnel, as a result of the increased data and technology many maintenance organisations are in need of new kind of skill related to e.g. data analytics (Diez-Olivan et al., 2019). If an organisation decides to recruit new personnel based on their maintenance investment they should be aware of the share of costs to be allocated to the maintenance function. Allocating employees' time to different tasks and evaluating system underutilisation rates is likely to be based on subjective and inaccurate estimates. However the value generated by the decrease in underutilisation of data management resources could be significant to the investment decision and should be evaluated as a share of the costs of maintenance systems and personnel:

$$
V_{5}=\left(F_{a} * x_{a}\right)-\left(F_{b} * x_{b}\right)
$$

where $F_{a}$ is the annual cost of the data management resources before the investment, $x_{a}$ is the share of time the resources are unused before the investment, 
$F_{b}$ is the annual cost of the data management resources after the investment, and

$x_{b}$ is the share of time the resources are unused after the investment.

The value generated by decrease in waiting for data and decision making is possibly the most significant component of the total value. However it also includes uncertainty, and is challenging to evaluate accurately. In this paper this value component is addressed as

$$
V_{6}=A-B
$$

where $A$ is the annual cost of the actual maintenance work and the value of production lost due to asset breakdowns before the investment, and

$B$ is the same annual cost after the investment.

The maintenance costs in $A$ and $B$ include direct labour costs, direct materials, spare parts, tools, equipment, purchased services, administration and management, training, energy and utilities, other overheads, and the value of the production lost due to asset unavailability (see e.g. El-Haram \& Horner, 2002; Salonen \& Deleryd, 2011). The value of lost production caused by asset breakdowns is rarely included in the total maintenance costs in the existing standards (see BS EN 15341, 2007) because it is often a significant amount (multiple times bigger than the maintenance costs) (see e.g. Knapp \& Mahajan, 1998; Sinkkonen et al., 2013; Wu \& Clements-Croome, 2005) and is considered a significant issue that should not be allocated only to the maintenance function. However, the value of lost production has to be taken into account in maintenance investment decisions so in the WVD-model it is addressed as a part of the maintenance costs. Despite their importance the value of lost production and other indirect maintenance costs tend to be time-consuming to evaluate accurately, which is why they are often approximated based on average asset productivities, contribution margins, and downtimes (see Edwards et al., 2000).

The three common maintenance actions, ignoring run-to-fail, are referred to as corrective, predetermined, and condition based. Corrective maintenance aims to restore asset functionality after a failure, predetermined maintenance seeks to prevent failures based on time- or use-based maintenance, and condition-based maintenance relies on monitoring the actual condition of the asset to decide on the optimal maintenance actions (BS EN 13306, 2017). It is generally acknowledged that compared to corrective maintenance, adopting predetermined and condition-based maintenance strategies requires more resources although this can result in increased performance in terms of reduced probability of breakdowns, improved asset condition, less deficiencies in quality, and equipment life extension (Swanson, 2001). Optimal maintenance seeks to minimize the total costs, including the actual 
maintenance costs and the value of lost production (Wang \& Wang, 2015; Weinstein et al., 2009). Thus compared to planned maintenance, corrective maintenance is seen to be more costly in the end (Gulati, 2009).

In equation (1) $V_{6}$ is influenced by the uncertainty coefficient $\alpha$. This coefficient takes into account the quality of both the maintenance data and analyses used to support decision making:

$$
\alpha=P\left(\beta_{2} \cup \gamma_{2}\right)-P\left(\beta_{1} \cup \gamma_{1}\right)=P\left(\beta_{2}\right)+P\left(\gamma_{2}\right)-P\left(\beta_{2} \cap \gamma_{2}\right)-P\left(\beta_{1}\right)-P\left(\gamma_{1}\right)+P\left(\beta_{1} \cap \gamma_{1}\right)
$$

where $P\left(\beta_{I}\right)$ is the probability of the maintenance data being incorrect before the investment,

$P\left(\beta_{2}\right)$ is the probability of the maintenance data being incorrect after the investment,

$P\left(\gamma_{1}\right)$ is the probability of conducting the data analyses incorrectly before the investment, and

$P\left(\gamma_{2}\right)$ is the probability of conducting the data analyses incorrectly after the investment.

Thus the probabilities of the data and the analyses being incorrect need to be estimated, and the probability of both incorrect data and analyses would need to be identified. In practice these probabilities could either be estimated based on the views of industrial experts, or be evaluated based on a quality analysis of a sample of the data in question.

\subsection{Evaluating the profitability of the investment}

As with any investment, the profitability assessment requires studying the actual investment costs in relation to the decreased waste (which impacts the annual operating and maintenance costs) addressed above. Depending on the objective and scope of the maintenance investment, the investment costs may include the costs of software, hardware, labour, training, consulting, etc. (see e.g. O'Donoghue \& Prendergast, 2004). There is a number of established methods to evaluate the profitability and feasibility of an investment, including for example the payback period (see e.g. Yard, 2000), net present value (Liljeblom \& Vaihekoski, 2004), and internal rate of return (Juhász, 2011). In this paper the investments are evaluated based on the net present value, calculated from the annual value $V$ as:

$N P V=\sum_{T=1}^{t} \frac{V}{(1+i)^{T}}-I$

where $N P V$ is the net present value of the investment,

$i$ is the discount rate,

$t$ is an estimate of the life cycle of the investment or the analysis period, and

$I$ is the total initial investment. 
Out of the investment appraisal methods, NPV was selected because it has been extensively adopted in practice, presents the results in monetary terms, and takes the time value of money into account. However, it is important to state that this method is based on variables such as $i$ and $t$, both of which are prone to uncertainty and more or less subjective assumptions (see Juhász, 2011). To overcome this issue, sensitivity analyses is often used to study the impact of uncertainty on the profitability of investments.

\section{Case example}

\subsection{Introduction to the case}

The case focuses on a company which manufactures a range of parts for the automotive industry. The analysis is based upon a three-shift production plant operating in the UK. Currently the company uses manual forms to collect data on their maintenance, and inserts the data into electronic spreadsheets once a day. The maintenance managers feel that they cannot use the data for improving their maintenance processes, because it is mostly focused on maintenance and breakdown times, and important information such as the data on failure causes are missing. Accordingly, the maintenance engineers at the production plant are currently using $70 \%$ of their time on breakdowns and repairs, as opposed to only $2.9 \%$ on preventive maintenance tasks.

The maintenance managers are thinking about investing in the data management of the maintenance process to implement a CMMS and to develop their maintenance policies towards predetermined, instead of corrective, maintenance. Referring to the three literature-based decision dimensions of maintenance investments (see Tam \& Price, 2008) as presented above in section 2.1, the main objectives of the company are to increase production (output dimension), decrease unplanned breakdowns (risk dimension), and improve data-based decision making (resources dimension). There are 15 production lines in the plant, of which the company is particularly interested in three that are causing a large share of the breakdowns of the plant and are important in terms of plant productivity: Floor Carpet 3 (FC3), Foam Line 1 (FL1), and Foam Line 2 (FL2). In this case example, the value of additional data and CMMS in the maintenance management of the selected production lines is analysed. The data used for the analysis includes the selected production plant's maintenance and breakdown times from 1 January to 22 June 2018. In addition the maintenance manager of the plant was interviewed to gain insight on the maintenance and data management processes.

\subsection{Annual costs and benefits of the case investment}

In the case example, $V_{1}$ and $V_{2}$ (the value generated by decrease in unnecessary data) are assumed to be insignificant and are thus omitted. The case company is currently manually collecting data which could 
be of value if they adopt a predetermined and/or condition-based maintenance strategies instead of the corrective maintenance they are currently running.

Regarding the unnecessary transfer of data, investing in the CMMS would remove the need to manually insert the collected data into electronic spreadsheets. Currently a production planner uses $1 \mathrm{~h}$ per production shift to transfer the data into the spreadsheets. With regard to the breakdowns in the production plant during the research period, 7.8\% occurred at FC3, 25.1\% at FL1 and 21.0\% at FL2. Thus $53.9 \%$ of the breakdowns in the plant can be reached through the three selected production lines. Allocated based on the number of breakdowns per each production line during the research period, the annual time saved from transferring the data into spreadsheets would be $20.3 \mathrm{~h}$ for FC3, 65.2h for FL1, and $54.5 \mathrm{~h}$ for FL2. Based on public sources, the employee cost of the production planner's time is estimated to be $13.3 £ / h$. Thus:

$$
V_{3}=(20.3 h+65.2 h+54.5 h) * 13.3 £ / h=1,862 £
$$

Data processing includes several tasks embedded in the decision making process. A summary of these tasks before and after the investment is given in Table 1. Currently the case company collects data before each shift handover: a maintenance report sheet from each maintenance engineer who finishes their shift, maintenance shift handover details from each shift, and a production data summary from each shift. To reach the data needed for supporting maintenance decision making, after the investment the company would collect data on each maintenance event. This data would replace the data currently included in the maintenance report sheets and the maintenance shift handover details. It has been assumed that the number of maintenance events would remain unchanged (a part of the breakdowns would be replaced by preventive maintenance events), that documenting the production data would be $50 \%$ faster with a CMMS compared to the current manual process, and that the maintenance managers of the case plant would use an additional $1 \mathrm{~h}$ per each shift to analyse the new data created by the investment. Currently the data is not systematically analysed and exploited because key information is missing.

Table 1. The impact of the investment on the processing of data.

\section{[Place Table 1 here]}

It can be concluded that $V_{4}$ equals $-10,413 £(6,221 £-16,634 £)$, as implementing the CMMS and a predetermined maintenance strategy would produce more data to be processed.

If the case company were able to pilot the CMMS on only the three selected production lines, the software would be somewhat underutilized, at least before implementing it on a wider scale. Thus the whole cost of the software would at first be allocated to the three pilot lines. $V_{5}$, caused by 
underutilization of data management resources, could thus be assessed based on the costs of the selected CMMS software. However in this case study no specific CMMS software has been selected by the company, and the costs related to the software and its installation are not known in detail. Thus $V_{5}$ is omitted at this point, and the software costs are discussed later as part of the investment costs.

In this case example the value of decreased waiting in the data management process, $V_{6}$, is related to the availability of additional data as a result of the investment. With the correct data (failure root causes, reliabilities, repair times, performance and cost rates, etc.) the case company will be able to conduct predetermined maintenance, instead of the failure-based corrective maintenance they are currently running. Predetermined maintenance would prevent a share of the breakdowns (Meller \& Kim, 1996), which would increase the annual production time and sales (assuming that there is a demand for the increased production). Table 2 shows how the value of this increased production after the investment has been assessed.

In practice predetermined maintenance schedules are often based on equipment suppliers' recommendations or experience-based assumptions of the maintenance personnel (Vilarinho et al., 2017). However, to increase the impact of the maintenance programme, the schedule should be defined based on a Failure Modes and Effects Analysis (FMEA), taking the specific failures and their root causes into account. Chen (2013) discussed that introducing a FMEA-based predetermined maintenance schedule decreased breakdowns by $25 \%$. Komonen (2002) documented a prevention rate of $34 \%$ in three-shift production plants of various industries in Finland during 1996-1997. Ruifeng and Subramaniam (2012) studied Kanban controlled assembly lines and reported a 50\% reduction in the probability of interruption after introducing predetermined maintenance. Muchiri et al. (2014) highlighted that the performance of a predetermined maintenance policy (compared to a corrective one) is higher when the reliability of the equipment is poor. Consequently, when the equipment is reliable, implementing a preventive maintenance programme can create problems and increase costs without resulting in an increase in value. The share of breakdown-induced downtime of the production time is $7.73 \%$ for FC3, 19.95\% for FL1, and 17.96\% for FL2. Based on the notions presented above, a prevention rate of $30 \%$ (for FC3 with a higher reliability), and $40 \%$ (for FL1 and FL2 with a larger share of breakdowns) has been assumed.

The assumptions described on prevention rates for each production line are likely to have a strong impact on the profitability of the investment. There is a lot of existing research on modelling the optimal predetermined maintenance intervals for various systems. Most of these models are case specific and assume that the decision maker knows the system's failure distribution in detail (Cavalier \& Knapp, 1996). Common ways to present the failure probability functions are e.g. Weibull distributions for agerelated failures (Nguyen \& Chou, 2018; Sarker \& Faiz, 2016), and exponential functions for constant failure rates (Peters \& Madlener, 2017). In this paper we pursue a more general model to support the 
decision makers in evaluating the profitability of an investment which would, later on, include the FMEA to study the failure distributions of the system(s) in question.

It has been assumed that the direct maintenance costs (direct labour and materials) would not change after adopting the predetermined maintenance programme. The average value of an additional hour of production has been estimated based on the publicly available financial information of the case company from 2018 (annual sales, the share of variable costs, and the tax rate). Each production line in the plant has been assumed to be equal in terms of value of production per hour, because the case company considers the prices and profit margins of individual products to be sensitive data.

Table 2. The impact of the investment on the lost production.

\section{[Place Table 2 here]}

To calculate the uncertainty coefficient $\alpha$, estimates are needed on the probabilities of poor quality data and analyses before and after the investment. According to Tayi and Ballou (1998), data quality goes hand in hand with fitness for use and thus is a relative and subjective concept. Measures of data quality include e.g. accuracy, completeness, consistency, timeliness, interpretability, and accessibility. However these qualities are often difficult for the data users to evaluate objectively, and thus the users often end up trusting that the data is of high quality even though the matter has not been properly addressed (Cappiello et al., 2004). To present an evaluation of the data quality, in this case example the case data was reviewed for visible analysis errors (\#REF! error codes in the spreadsheet) in the production line downtime summary data. Based on the findings, the current probability of incorrect analysis is estimated to be $0.27 \%$. This is assumed to reduce to $0.00 \%$ after the investment. Regarding the probability of incorrect data, the authors did not have a reliable way of assessing the quality of the actual case data since there is no way to check if the manually collected data is accurate. Instead, a general observation on the quality of data is used: according to a recent global survey, organisations with manual and excel-based data management processes reported that $41 \%$ of their data could be inaccurate, whereas organizations that used more sophisticated data management tools reported an average of $27 \%$ or less (Experian Data Quality, 2015). Inserting these figures into equation (8), and assuming that the occurrence of poor quality data and poor quality analyses are independent events, $\alpha$ is estimated to be -0.13 . Thus the investment increases the quality of data and analyses, which will be taken into account when calculating the total value of the investment.

Through inserting the figures presented above into equation (1), an estimate of the annual added value of the investment is:

$$
V=1,862 £-10,413 £+(1+0.13) * 65,428 £=65,383 £
$$




\subsection{Profitability of the case investment}

The case company have yet to identify specific CMMS software or specific additional data items to be collected. This creates uncertainty regarding the investment costs. Therefore, rather than calculating the NPV based on the costs, the authors opted to calculate a break-even level of the investment costs based on a predefined $N P V$. The logic is similar to that of target costing (see e.g. Monden \& Hamada, 1991), the objective of which is traditionally to establish a target cost for a product in its planning or design stage, based on predetermined target levels of sales price and profit margin.

From equation (9) we get:

$$
I=\sum_{T=1}^{t} \frac{V}{(1+i)^{T}}-N P V
$$

To calculate the break-even level of investment costs, $N P V$ is set to 0 . There is no universal solution to choosing the discount rate $i$. For instance Harrison (2010) recommends including the selected rate into a sensitivity analysis to decrease the uncertainty. One of the commonly used methods in choosing the discount rate is to calculate the Weighted Average Cost of Capital (WACC) of the company (see Keane, 1975). Following this method and using the publicly available consolidated financial statement of the case company, the discount rate has been calculated as:

$$
i=\frac{i_{D} * D+i_{E} * E}{D+E}
$$

where $i_{D}$ is the average interest rate of debt,

$D$ is the amount of debt,

$i_{E}$ is the return on equity, and

$E$ is the amount of shareholder equity.

For the case company the WACC-based discount rate is:

$$
i=\frac{i_{D} * D+i_{E} * E}{D+E}=\frac{4.6 \% * 2,584 M €+19.5 \% * 4,071 M €}{2,584 M €+4,071 M €}=13.7 \%
$$

The investment lifecycle $t$ is an estimate of how long the data management system (including the CMMS and the data exploitation processes in maintenance) is expected to outperform other alternatives. According to Richmond et al. (2006) the software lifecycle is affected by a number of variables including project scope, level of customization, and fit with technology standards. In this case example the investment lifecycle is set to 3 years to represent the dynamic pace of ICT-related investments. 
Based on equation (12), the break-even level of the investment costs is:

$$
I=\frac{65,383 £}{(1+0.137)^{1}}+\frac{65,383 £}{(1+0.137)^{2}}+\frac{65,383 £}{(1+0.137)^{3}}-0 £=152,563 £
$$

According to Labib (2004), commercial CMMS solutions with features for data collection and analysis typically cost in excess of $£ 10,000$, whereas features for real-time data analysis increase the price to at least 30,000£. Real-time analysis is usually related to condition-based maintenance, and at this point would not be required by the case company. Thus based on the analysis presented above, investing in the CMMS and additional maintenance data seems very profitable to the case company. Even significant changes in parameters such as the assumed failure prevention rates, $\alpha$ (the uncertainty coefficient describing the quality of data and analyses), $i$ (the discount rate used to describe the WACC of the company), or $t$ (the assumed lifecycle of the investment) would not turn the investment unprofitable.

\section{Conclusion}

This paper presented the analytical WVD-model to quantify the value of data in maintenance investments. The model is designed and developed on the principle of eliminating waste to increase value, which has not been previously extensively discussed in the context of data management. The big data hype has led many organizations into gathering data without systematic exploitation plans. However in terms of the output, risk, and resource dimensions (see Tam \& Price, 2008) of data-based investments it is crucial to evaluate if the benefits created by the investment will exceed the additional costs. This has previously been discussed by Pape (2016), who applied his model in human resources.

The managerial use of the WVD-model has been demonstrated through an empirical case example. However applying the model in practical decision making situations still involves some aspects which have not been extensively studied in the literature. For example, in the WVD-model the impact of data and analysis quality is measured through a simple uncertainty coefficient $\alpha$. Further research should be directed at studying how the quality affects the value of data and analyses in maintenance decision making, how the quality should be measured, and what is the current state-of-practice in industry. Another limitation of the presented WVD-model is related to the maintenance types adopted by the applying organizations. In the case example presented in this paper, corrective and predetermined maintenance were considered. It would be considerably more complex to quantify the value of data in a context where condition-based maintenance is applied. Thus further research should study how the specific features of condition-based maintenance (e.g. large real-time datasets, integration of various data, and human-machine interaction) impact the value modelling process.

\section{References}


Alfonso, L., Mukolwe, M.M. and Di Baldassarre, G. (2016), "Probabilistic flood maps to support decision-making: mapping the value of information", Water Resources Research, Vol. 52 No. 2, pp. 1026-1043.

Alsyouf, I. (2009), "Maintenance practices in Swedish industries: survey results", International Journal of Production Economics, Vol. 121 No. 1, pp. 212-223.

Andersson, R., Manfredsson, P. and Lantz, B. (2015), "Total productive maintenance in support processes: an enabler for operation excellence", Total Quality Management, Vol. 26 No. 9-10, pp. 1042-1055.

Baglee, D., Marttonen, S. and Galar, D. (2015), “The need for big data collection and analyses to support the development of an advanced maintenance strategy", in Proceedings of the $11^{\text {th }}$ International Conference on Data Mining, Las Vegas, Nevada, USA, July 27-30, pp. 3-9.

Bennett, J.R., Maxwell, S.L., Martin, A.E., Chadès, I., Fahrig, L. and Gilbert, B. (2018), "When to monitor and when to act: value of information theory for multiple management units and limited budgets", Journal of Applied Ecology, Vol. 55 No. 5, pp. 2102-2113.

Bevilacqua, M., Ciarapica, F.E. and Paciarotti, C. (2015), "Implementing lean information management: the case study of an automotive company”, Production Planning \& Control, Vol. 26 No. 10, pp. 753-768.

BS EN 13306 (2017), “Maintenance. Maintenance terminology”, BSI Standards Ltd., ISBN 978-0-58090370-0.

BS EN 15341 (2007), “Maintenance - Maintenance key performance indicators”, BSI Standards Ltd., ISBN 978-0-580-50611-6.

BS ISO 55001 (2014), “Asset management. Management systems - Requirements”, BSI Standards Ltd., ISBN 978-0-580-75128-8.

Bucherer, E. and Uckelmann, D. (2011), "Business models for the Internet of Things", in Uckelmann, D., Harrison, M. and Michahelles, F. (Eds.), Architecting the Internet of Things, Springer, e-ISBN 9783-642-19157-2.

Candell, O., Karim, R. and Söderholm, P. (2009), "eMaintenance - information logistics for maintenance support”, Robotics and Computer-Integrated Manufacturing, Vol. 25 No. 6, pp. 937-944. 
Cappiello, C., Francalanci, C. and Pernici, B. (2004), "Data quality assessment from the user's perspective", in Proceedings of the 2004 International Workshop on Information Quality in Information Systems (IQIS'04), 18 June, Paris, France, ISBN 1-58113-902-0, pp. 68-73.

Cavalier, M.P. and Knapp, G.M. (1996), "Reducing preventive maintenance cost error caused by uncertainty", Journal of Quality in Maintenance Engineering, Vol. 2 No. 3, pp. 21-36.

Chen, C.-C. (2013), “A developed autonomous preventive maintenance programme using RCA and FMEA”, International Journal of Production Research, Vol. 51 No. 18, pp. 5404-5412.

Chen, H.-M., Kazman, R. and Matthes, F. (2015), "Demystifying big data adoption: beyond IT fashion and relative advantage", in DIGIT 2015 Proceedings, Paper 4.

Dewan, S. and Min, C.-K. (1997), "The substitution of information technology for other factors of production: a firm level analysis”, Management Science, Vol. 43 No. 12, pp. 1660-1675.

Diez-Olivan, A., Del Ser, J., Galar, D. and Sierra, B. (2019), "Data fusion and machine learning for industrial prognosis: trends and perspectives towards Industry 4.0", Information Fusion, Vol. 50 No. 1, pp. 92-111.

Edwards, D.J., Holt, G.D. and Harris, F.C. (2000), "A model for predicting plant maintenance costs", Construction Management and Economics, Vol. 18 No. 1, pp. 65-75.

El-Haram, M. and Horner, M. (2002), "Factors affecting housing maintenance cost", Journal of Quality in Maintenance Engineering, Vol. 8 No. 2, pp. 115-123.

El Kadiri, S., Grabot, B., Thoben, K.-D., Hribernik, K., Emmanouilidis, C., von Cieminski, G. and Kiritsis, D. (2016), "Current trends on ICT technologies for enterprise information systems", Computers in Industry, Vol. 79 No. 1, pp. 14-33.

Erkoyuncu, J.A., Khan, S., Eiroa, A.L., Butler, N., Rushton, K. and Brocklebank, S. (2017), "Perspectives on trading cost and availability for corrective maintenance at the equipment type level", Reliability Engineering and System Safety, Vol. 168 No. 1, pp. 53-69.

Experian Data Quality (2015), “The data quality benchmark report. An Experian Data Quality white paper", available at: http://go.experian.com/global-research-report-2015 (accessed 18 March 2019).

Gulati, R. (2009), Maintenance and Reliability - Best Practices, Industrial Press Inc., New York, NY. 
Günther, W.A., Mehrizi, M.H.R., Huysman, M. and Feldberg, F. (2017), "Debating big data: a literature review on realizing value from big data", Journal of Strategic Information Systems, Vol. 26 No. 3, pp. 191-209.

Gupta, S., Sharma, M. and Sunder, V.M. (2016), "Lean services: a systematic review", International Journal of Productivity and Performance Management, Vol. 65 No. 8, pp. 1025-1056.

Harrison, M. (2010), "Valuing the future: the social discount rate in cost-benefit analysis", Visiting researcher paper, Productivity Commission, Canberra.

Hicks, B.J. (2007), "Lean information management: understanding and eliminating waste", International Journal of Information Management, Vol. 27 No. 4, pp. 233-249.

Huang, J., Bian, Y. and Cai, W. (2012), "Weapon equipment lean maintenance strategy research", in Proceedings of the International Conference on Quality, Reliability, Risk, Maintenance, and Safety Engineering (ICQR2MSE), Chengdu, China, ISBN 978-1-4673-0788-8, pp. 1217-1221.

Imran, M., ul Hameed, W. and ul Haque, A. (2018), "Influence of Industry 4.0 on the production and service sectors in Pakistan: evidence from textile and logistics industries", Social Sciences, Vol. 7 No. 12, p. 246.

Juhász, L. (2011), "Net present value versus internal rate of return”, Economics \& Sociology, Vol. 4 No. 1, pp. 46-53.

Jylhä, T. and Junnila, S. (2013), "Learning from lean management - going beyond input-output thinking”, Facilities, Vol. 31 No. 11/12, pp. 454-467.

Kadan, O. and Manela, A. (2018), "Estimating the value of information", available at SSRN: https://ssrn.com/abstract=2788751 or http://dx.doi.org/10.2139/ssrn.2788751 (accessed 20 March 2019).

Kamble, S.S., Gunasekaran, A. and Gawankar, S.A. (2018), "Sustainable Industry 4.0 framework: a systematic literature review identifying the current trends and future perspectives", Process Safety and Environmental Protection, Vol. 117 No. 1, pp. 408-425.

Kans, M. (2013), "IT practices within maintenance from a systems perspective", Journal of Manufacturing Technology Management, Vol. 24 No. 5, pp. 768-791. 
Keane, S.M. (1975), Investment selection criteria: an examination of the theory of the internal rate of return and of the investment discount rate under conditions of uncertainty, PhD Thesis, University of Glasgow, available at: http://theses.gla.ac.uk/2861/ (accessed 21 March 2019).

Keltanen, M. (2013), "Why 'lean data' beats big data”, available at: https://www.theguardian.com/medianetwork/media-network-blog/2013/apr/16/big-data-lean-strategy-business (accessed 25 March 2019).

Kinnunen, S.-K., Marttonen-Arola, S., Ylä-Kujala, A., Kärri, T., Ahonen, T., Valkokari, P. and Baglee, D. (2016), "Decision making situations define data requirements in fleet asset management", in Proceedings of the $10^{\text {th }}$ World Congress in Engineering Asset Management (WCEAM 2015), Lecture Notes in Mechanical Engineering (2195-4356), Springer, pp. 357-364, ISBN 978-3-319-27062-3.

Kleinberg, J., Papadimitriou, C. and Raghavan, P. (1998), “A microeconomic view of data mining”, Data Mining and Knowledge Discovery, Vol. 2 No. 4, pp. 311-324.

Knapp, G. and Mahajan, M. (1998), "Optimization of maintenance organization and manpower in process industries”, Journal of Quality in Maintenance Engineering, Vol. 4 No. 3, pp. 168-183.

Komonen, K. (2002), “A cost model of industrial maintenance for profitability analysis and benchmarking", International Journal of Production Economics, Vol. 79 No. 1, pp. 15-31.

Konecranes (2018), “Annual review 2018", available at: https://www.konecranes.com/sites/default/files/2019-03/Konecranes-Annual-Review-2018.pdf (accessed 23 May 2019).

Labib, A.W. (2004), “A decision analysis model for maintenance policy selection using a CMMS”, Journal of Quality in Maintenance Engineering, Vol. 10 No. 3, pp. 191-202.

Liljeblom, E. and Vaihekoski, M. (2004), "Investment evaluation methods and required rate of return in Finnish publicly listed companies", Finnish Journal of Business Economics, Vol. 53 No. 1, pp. 9-24.

Marttonen-Arola, S. and Baglee, D. (2019), "Assessing the information waste in maintenance management processes", Journal of Quality in Maintenance Engineering, Vol. ahead-of-print No. ahead-of-print, https://doi.org/10.1108/JQME-11-2018-0100.

Meller, R.D. and Kim, D.S. (1996), "The impact of preventive maintenance on system cost and buffer size”, European Journal of Operational Research, Vol. 95 No. 3, pp. 577-591. 
Monden, Y. and Hamada, K. (1991), "Target costing and Kaizen costing in Japanese automobile companies", Journal of Management Accounting Research, Vol. 3 (fall), pp. 16-34.

Mostafa, S. Lee, S.-H., Dumrak, J., Chileshe, N. and Soltan, H. (2015), "Lean thinking for a maintenance process", Production \& Manufacturing Research, Vol. 3 No. 1, pp. 236-272.

Muchiri, P.N., Pintelon, L., Martin, H. and Chemweno, P. (2014), "Modelling maintenance effects on manufacturing equipment performance: results from simulation analysis", International Journal of Production Research, Vol. 52 No. 11, pp. 3287-3302.

Nguyen, T.A.T. and Chou, S.-Y. (2018), "Maintenance strategy selection for improving costeffectiveness of offshore wind systems", Energy Conversion and Management, Vol. 157 No. 1, pp. 86-95.

Obeysekare, E., Marucci, A. and Mehta, K. (2016), "Developing a lean data management system for an emerging social enterprise", in Proceedings of the IEEE Global Humanitarian Technology Conference, 13-16 October, Seattle, WA, USA, ISBN 978-1-5090-2432-2, pp. 54-61.

O'Donoghue, C.D. and Prendergast, J.G. (2004), "Implementation and benefits of introducing a computerized maintenance management system into a textile manufacturing company", Journal of Materials Processing Technology, Vol. 153-154 No. 1, pp. 226-232.

Pape, T. (2016), "Prioritising data items for business analytics: framework and application to human resources", European Journal of Operational Research, Vol. 252 No. 2, pp. 687-798.

Peters, L. and Madlener, R. (2017), "Economic evaluation of maintenance strategies for ground-mounted solar photovoltaic plants", Applied Energy, Vol. 199 No. 1, pp. 264-280.

Richmond, W., Nelson, P. and Misra, S. (2006), "An empirical analysis of software life spans to determine the planning horizon for new software", Information Technology and Management, Vol. 7 No. 2, pp. 131-149.

Roy, R., Stark, R., Tracht, K., Takata, S. and Mori, M. (2016), “Continuous maintenance and the future foundations and technological challenges", CIRP Annals - Manufacturing Technology, Vol. 65 No. 2, pp. 667-688. 
Ruifeng, C. and Subramaniam, V. (2012), "Increasing production rate in Kanban controlled assembly lines through preventive maintenance", International Journal of Production Research, Vol. 50 No. 4, pp. 991-1008.

Salonen, A. and Deleryd, M. (2011), "Cost of poor maintenance. A concept for maintenance performance improvement", Journal of Quality in Maintenance Engineering, Vol. 17 No. 1, pp. 63-73.

Sarker, B.R. and Faiz, T.I. (2016), "Minimizing maintenance cost for offshore wind turbines following multi-level opportunistic preventive strategy”, Renewable Energy, Vol. 85 No. 1, pp. 104-113.

Sinkkonen, T., Marttonen, S., Tynninen, L. and Kärri, T. (2013), ”Modelling costs in maintenance networks", Journal of Quality in Maintenance Engineering, Vol. 19 No.3, pp. 330-344.

Staats, B.R., Brunner, D.J. and Upton, D.M. (2011), "Lean principles, learning, and knowledge work: evidence from a software services provider", Journal of Operations Management, Vol. 29 No. 5, pp. 376-390.

Swanson, L. (2001), "Linking maintenance strategies to performance", International Journal of Production Economics, Vol. 70 No. 3, pp. 237-244.

Takata, S., Inoue, Y., Kohda, T., Hiraoka, H. and Asama, H. (1999), "Maintenance data management system”, Annals of the CIRP, Vol. 48 No. 1, pp. 389-392.

Tam, A.S.B. and Price, J.W.H. (2008), “A generic asset management framework for optimising maintenance investment decision", Production Planning \& Control, Vol. 19 No. 4, pp. 287-300.

Tayi, G.K. and Ballou, D.P. (1998), "Examining data quality", Communications of the ACM, Vol. 41 No. 2, pp. 54-57.

Verhagen, W.J.C., de Vrught, B., Schut, J. and Curran, R. (2015), "A method for identification of automation potential through modelling of engineering processes and quantification of information waste", Advanced Engineering Informatics, Vol. 29 No. 3, pp. 307-321.

Vilarinho, S., Lopes, I. and Oliveira, J.A. (2017), "Preventive maintenance decisions through maintenance optimization models: a case study", Procedia Manufacturing, Vol. 11 No. 1, pp. 11701177. 
Wang, W. and Wang, H. (2015), "Preventive replacement for systems with condition monitoring and additional manual inspections", European Journal of Operational Research, Vol. 247 No. 2, pp. $459-471$.

Weinstein, L., Vokurka, R.J. and Graman, G.A. (2009), "Costs of quality and maintenance: improvement approaches", Total Quality Management, Vol. 20 No. 5, pp. 497-507.

Wienker, M., Henderson, K. and Volkerts, J. (2016), "The computerized maintenance management system - an essential tool for world class maintenance", Procedia Engineering, Vol. 138 No. 1, pp. $413-420$.

Wu, S. and Clements-Croome, D. (2005), "Optimal maintenance policies under different operational schedules", IEEE Transactions on Reliability, Vol. 54 No. 2, pp. 338-346.

Yard, S. (2000), "Developments of the payback method", International Journal of Production Economics, Vol. 67 No. 2, pp. 155-167. 
Table 1. The impact of the investment on the processing of data.

\begin{tabular}{|c|c|c|c|c|}
\hline $\begin{array}{l}\text { Data processing } \\
\text { task }\end{array}$ & $\begin{array}{l}\text { Documenting the work before } \\
\text { shift handover }\end{array}$ & $\begin{array}{c}\text { Documenting } \\
\text { maintenance event } \\
\text { data }\end{array}$ & $\begin{array}{l}\text { Data analysis } \\
\text { and exploitation }\end{array}$ & TOTAL \\
\hline $\begin{array}{l}\text { Time and cost } \\
\text { required by the } \\
\text { current process } \\
\text { (annually) }\end{array}$ & $\begin{array}{c}465 \mathrm{~h} \\
6,221 £ \\
\\
\text { (15 min per maintenance report } \\
\text { sheet, } 20 \text { min per maintenance } \\
\text { shift handover, and } 20 \text { min per } \\
\text { production data summary) }\end{array}$ & $\begin{array}{l}\text { (Maintenance event } \\
\text { data not currently } \\
\text { recorded) }\end{array}$ & $\begin{array}{l}\text { (Currently not } \\
\text { properly } \\
\text { analysed and } \\
\text { exploited) }\end{array}$ & $\begin{array}{c}465 \mathrm{~h} \\
6,221 £\end{array}$ \\
\hline $\begin{array}{l}\text { Time and cost } \\
\text { required after } \\
\text { the investment } \\
\text { (annually) }\end{array}$ & $\begin{array}{c}70 \mathrm{~h} \\
946 £ \\
(10 \text { min per production data } \\
\text { summary) }\end{array}$ & $\begin{array}{c}681 \mathrm{~h} \\
8,989 £ \\
(5 \text { min per } \\
\text { maintenance event) }\end{array}$ & $\begin{array}{c}420 \mathrm{~h} \\
6,699 £ \\
(1 \text { h per shift })\end{array}$ & $\begin{array}{c}1,171 \mathrm{~h} \\
16,634 £\end{array}$ \\
\hline
\end{tabular}


Table 2. The impact of the investment on the lost production.

\begin{tabular}{|c|c|c|c|c|}
\hline $\begin{array}{l}\text { Production } \\
\text { line }\end{array}$ & $\begin{array}{c}\text { Share of } \\
\text { breakdowns of the } \\
\text { production time }\end{array}$ & $\begin{array}{l}\text { Assumed } \\
\text { prevention } \\
\text { rate }\end{array}$ & $\begin{array}{l}\text { Increase in production } \\
\text { time per year }\end{array}$ & $\begin{array}{l}\text { Value of the } \\
\text { increased production } \\
\text { per year }\end{array}$ \\
\hline FC3 & $7.73 \%$ & $30 \%$ & $145 \mathrm{~h}$ & $8,696 £$ \\
\hline FL1 & $19.95 \%$ & $40 \%$ & $498 \mathrm{~h}$ & $29,865 £$ \\
\hline FL2 & $17.96 \%$ & $40 \%$ & $448 \mathrm{~h}$ & $26,867 £$ \\
\hline In total & - & - & $1,091 \mathrm{~h}$ & $65,428 £$ \\
\hline
\end{tabular}

(3)

(n)

(1)

